\title{
Major pelvic injuries in equestrian sports
}

\author{
D A O'Farrell, F Irshad, B S Thorns, J P McElwain
}

\begin{abstract}
A series of pelvic and acetabular injuries caused by horse riding accidents is reported. The importance of wearing appropriate protective clothing when riding is emphasised.

(Br F Sports Med 1997;31:249-251)
\end{abstract}

Keywords: horse riding; pelvis; acetabulum

Horse riding accidents at both amateur and professional levels are associated with a wide variety of injuries. While most equestrian related injuries are of moderate severity, these accidents can also result in major lifethreatening fractures. This paper reports a series of pelvic and acetabular injuries caused by horse riding accidents and referred to this unit, which is a national referral centre for treatment of pelvic and acetabular fractures.

\section{Patients and methods}

Two hundred and five patients with pelvic and acetabular fractures were treated by operation at our unit between 1987 and 1995. Most of the injuries were caused by motor vehicle accidents or falls from a height. Nine patients sustained their injury while engaged in horse riding or horse racing activities over the past four years. All patients, except one who had died from a cause unrelated to his injury, responded to a questionnaire relating to their level of riding experience, the level of training of their horse, the circumstances of the accident, and the nature of protective riding equipment worn.

\section{Results}

Of a total of 205 pelvic and acetabular fractures requiring major pelvic internal fixation, nine injuries were sustained as the result of horse riding accidents. The mean age of the riders was 46 (range 18-75) years. Seven were men and two were women. Eight of the patients were very experienced amateur riders, with a mean riding experience of 30 (range 10-50) years, and one was a professional jockey. Six of the riders had previously been involved in minor horse riding accidents.

In five cases the horse fell on to the patient causing a crush injury, while four of the riders were thrown clear of the horse and struck the ground. Five patients had complete disruption of the pelvic ring involving symphyseal diastasis (fig 1) and sacroiliac joint separation (fig 2), referred to as an open book" pelvic injury. These were treated with early application of a pelvic external fixator to stabilise the pelvis and reduce blood loss. Open reduction and internal fixation of the sacroiliac joint and pubic symphysis (fig 3 ) was then performed at 7-10 days. Two patients had fractures of the ilium without disruption of the pelvic ring, and two patients had fractures of the acetabulum, one of the posterior acetabular wall, and one of the anterior column, all of which were managed surgically with open reduction and internal fixation of the fracture within one week of the accident.

The mean follow up time since pelvic surgery was 17 (range 1-40) months. The mean hospital stay was 24 (range 11-45) days. One patient was injured by an untrained horse which knocked her down in a stableyard; the remaining eight horses, all of which were mounted at the time of the accident, had been fully schooled. Two of the accidents occurred during a hunt and in both cases the riders were trained and experienced in hunting. All riders were familiar with the horse from which they fell. All riders wore a helmet with a retaining strap when they fell and none of the helmets was damaged by the fall. No riders wore body protectors which are currently recommended for horse riding. ${ }^{1}$ None of the riders had consumed alcohol before their accident. Five patients have ridden horses since the accident while four feel they will not be able to ride

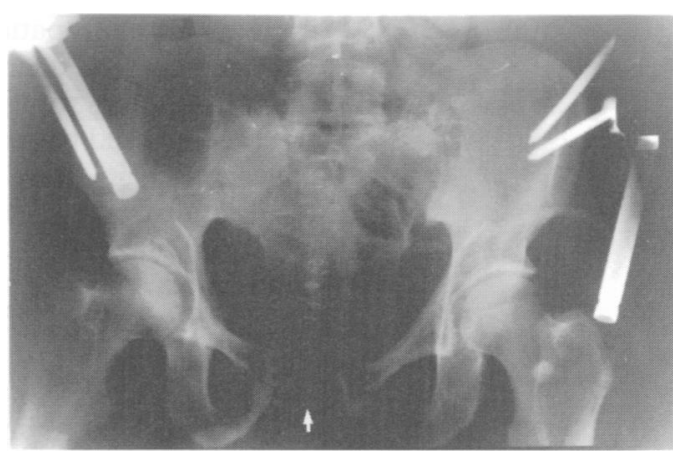

Figure 1 Pelvic radiograph showing complete disruption of the pelvic ring with diastasis of the pubic symphysis (arrow).

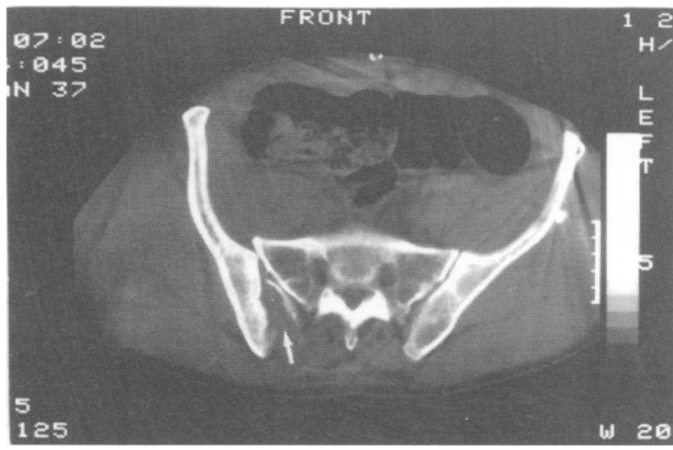

Figure 2 Computed tomography of the pelvis showing separation of the right sacroiliac joint (arrow). 
Table 1 Details of injuries sustained by the patients in this report

\begin{tabular}{|c|c|c|c|c|}
\hline $\begin{array}{l}\text { Patient } \\
\text { No }\end{array}$ & $\begin{array}{l}\text { Age } \\
\text { (years) }\end{array}$ & Equestrian activity & Mechanism of injury & Type of injury \\
\hline 1 & 51 & Hunting & Thrown from horse while jumping; struck hard ground & Dislocation of hip with fracture acetabulum \\
\hline 2 & 78 & Jumping a fence & Thrown from horse; struck hard ground & \\
\hline 3 & 45 & Training horse to jump & $\begin{array}{l}\text { Horse stumbled after clearing fence; } \\
\text { rider trapped under injured horse for } 10 \text { minutes }\end{array}$ & "Open book" injury of pelvis \\
\hline 4 & 38 & Jumping & Horse fell and crushed rider momentarily & "Open book" injury of pelvis \\
\hline 5 & 32 & Hunter trial & Fence too high; horse fell backwards on to rider & Fracture sacrum + ilium + pubic diastasis \\
\hline 6 & 66 & Cross-country riding & $\begin{array}{l}\text { Horse refused jump suddenly on slippery surface; } \\
\text { rider thrown; no crush }\end{array}$ & Anterior column acetabulum fracture \\
\hline 7 & 53 & Rounding cattle & $\begin{array}{l}\text { Horse took fright and reared on slippery surface } \\
\text { landing on rider }\end{array}$ & Lateral compression fracture \\
\hline 8 & 38 & Schooling & Kicked on pelvis while leading a fresh horse & Fracture of iliac wing \\
\hline 9 & 18 & Racehorse training & $\begin{array}{l}\text { Horse reared at fence and fell; jockey crushed as } \\
\text { foot caught in stirrup }\end{array}$ & "Open book" injury and acetabular fracture \\
\hline
\end{tabular}

again. Five patients have returned to their original occupation since their pelvic surgery, while three have not. Four patients have returned to other sporting activities including golf, soccer, tennis, and squash. The mean time missed from work owing to the injury was 6.5 (range 2-12) months.

\section{Discussion}

The overall injury rate from horse riding accidents has been reported as one serious injury per 350 riding hours in the $\mathrm{UK}^{2}$ and 0.6 per 1000 riding hours in the USA. ${ }^{3}$ Most horse riding injuries are relatively minor in nature ${ }^{45}$ but up to $15 \%$ require hospital admission. ${ }^{6}$ The majority $(57 \%)$ of deaths due to horse riding accidents are secondary to head injuries. ${ }^{78}$ In a report by Pounder, ${ }^{9}$ of 18 riding related deaths, 14 were caused by head injuries.

Horse riding accidents may also result in severe pelvic injuries as described here, although this subgroup has not been well studied in the literature. Major fractures of the pelvis are generally associated with a high energy impact, and all patients with these injuries require the same degree of emergency resuscitation as other multiple trauma victims. The fractures caused by horse riding accidents were comparable in type and severity to those resulting from high velocity road accidents and falls from buildings. Rapid referral to a regional centre with the necessary facilities and expertise to manage these fractures is critical, as the quality of the clinical result has been shown to be directly related to the timing of surgery. ${ }^{10} 11$ In particular, these injuries are associated with a high risk of massive retroperitoneal haemorrhage, which is potentially fatal, and injuries to the bladder, urethra, and rectum, which must be recognised early. ${ }^{12}$

Table 1 shows the mode of injury in each of our patients. Five of the riders were crushed by the horse, sustaining a lateral compression or "open book" type of injury. Burgess ${ }^{13}$ remarks that the type of crush injury depends on the position of the rider when crushed, the direction from which the force comes, and whether the force is a direct impact, or is changing position relative to the victim producing a combination injury. He states that in many crush injuries the initial injury causes a lateral compression type injury, but then the victim is rolled over and an anteroposterior force is applied to the pelvis.
However, when riders are thrown clear of the horse (fig 4) their injury is caused by striking the ground forcibly, and this mechanism of injury is more likely to produce a fracture of the acetabulum which may be accompanied by dislocation of the hip. Three of our patients sustained fractures of the acetabulum. The pathoanatomy of acetabular fractures depends on the position of the femoral head at the time of impact ${ }^{14}:$ a posterior column fracture is more likely to result if the femoral head is internally rotated, and an anterior column fracture if the head is externally rotated. The femoral head is in a neutral or slightly externally rotated position while the rider is mounted, but either of these positions may occur when the rider strikes the ground.

It is of note that all of the riders in our group were very experienced handlers of horses. Only in five cases did the horse fall on the rider

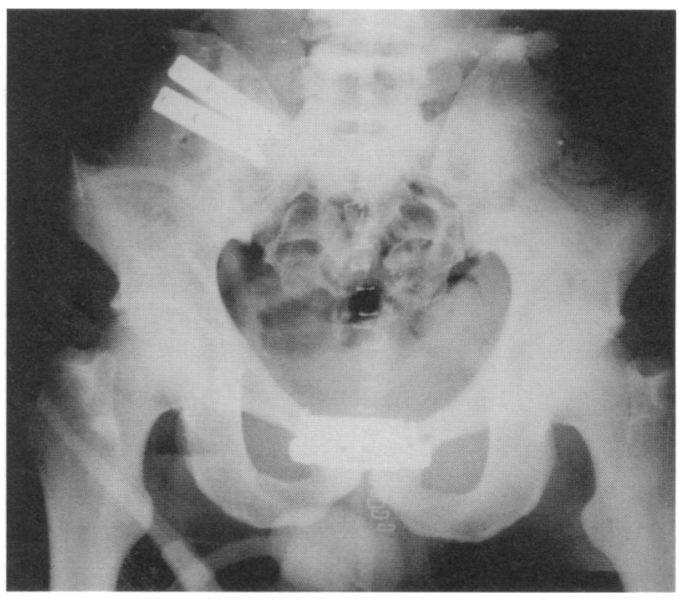

Figure 3 Postoperative pelvic radiograph showing plate fixation of the symphysis pubis and right sacroiliac joint.

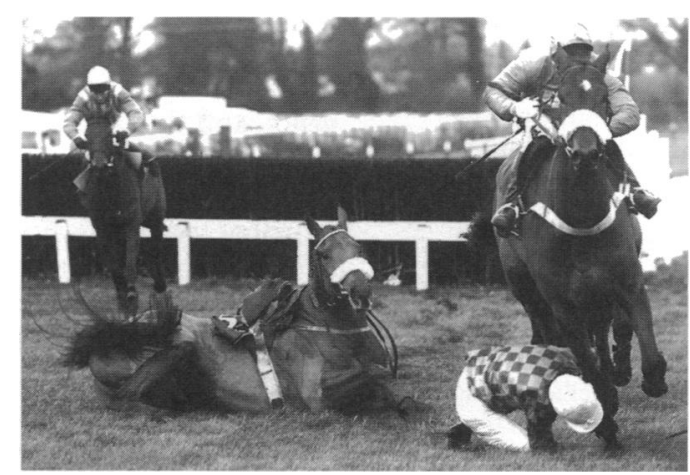

Figure 4 Acetabular fractures may result when a rider is thrown clear of the horse striking the ground forcibly, (Courtesy of the Irish Times.) 
causing a crush injury, the remainder sustaining a high energy impact on striking the ground. The fact that none of our subjects wore a body protector may have contributed to the severity of the injuries. These protective garments are commercially available and are manufactured according to British Equestrian Trade Association (BETA) standards. ${ }^{1}$ The use of helmets with retaining straps by all of our patients probably explains the absence of head injuries in the group, together with the fact that the energy of impact was concentrated at the pelvic region. Lack of riding experience was not a contributory factor in the group studied here, in contrast with the findings of Silver and Parry ${ }^{2}$ who found that one third of serious spinal injuries caused by falls from horses were associated with inadequate rider experience. The predominance of male riders in this population may be explained by the fact that our catchment area includes Kildare county which is an internationally renowned centre for horse breeding and training in which men are very involved at amateur and professional levels. A study from Newmarket in England similarly had a much greater ratio of men to women (almost seven to one) for horse related injuries. ${ }^{4}$ Doctors should inform their patients who ride horses about the hazards of equestrian sports and should emphasise the im- portance of using both a helmet and a body protector, as these may reduce the severity of the injury caused by a fall from a horse.

1 Parry JL. Injuries in equestrian sports. In: Renstrom PA, ed. The encyclopaedia of sports medicine: clinical practice of sports injury prevention and care. Oxford: Blackwell Scientific Publications, 1994:662.

2 Silver JR, Parry JM. Hazards of horse riding as a popula sport. Br ₹ Sports Med 1991;25:105-10.

3 Christey GL, Nelson DE, Rivara FP, Smith SM, Condie C. Horse back riding injuries among children and young adults. $\mathcal{F}$ Fam Pract 1994;39:148-52.

4 Edixhoven P, Sinha SC, Dandy DJ. Horse injuries. Injury 1981;12:279-82.

5 Anonymous. From the Centers for Disease Control. Injuries associated with horse-back riding, United States 1987-88. FAMA 1990;264:18-19.

6 Hobbs GD, Yealy DM, Rivas J. Equestrian injuries: five-year review. F Emerg Med 1994;12;143-5.

7 Nelson DE, Bixby-Hammet D. Equestrian injuries in children and young adults. Am $\mathcal{f}$ Dis Child 1992;146:61114.

8 Bixby-Hammett D. Paediatric equestrian injuries. Paediat rics 1992;89:1173-6.

9 Pounder D. The grave yawns for the horseman. Med f Aust 1984;141:632-5.

10 Brueton RN. A review of 40 acetabular fractures: the importance of early surgery. Injury 1993;24:171-4.

11 Johnson EE, Matta JM, Mast JW, Letournel E. Delayed reconstruction of acetabular fractures 21-120 days following injury. Clin Orthop 1994;305:20-30.

12 Robertson C, Redmond A. The management of majo trauma. In: Oxford handbooks in emergency medicine. 2nd ed. Oxford: Oxford University Press, 1994:102-5.

13 Burgess AR. Fractures of the pelvis. In: Rockwood CA Green DP, Bucholz RW, eds. Fractures in adults. Philadelphia: JB Lippincott Company, 1991:1414.

14 Tile M. Fractures of the acetabulum. In: Rockwood CA Green DP, Bucholz RW, eds. Fractures in adults. Philadelphia: JB Lippincott Company, 1991:1445.

\section{Commentary}

It will have been the experience of many doctors providing care for the injured rider that pelvic fractures are a cause for serious concern, and that a high index of suspicion must exist if a lethal outcome is to be avoided. This excellent paper draws attention to the severity of injury if a rider is crushed by a horse (weighing approximately $500 \mathrm{~kg}$ ) or, when thrown, is exposed to a high energy impact, particularly on contact with hard ground. The spectre of a closed massive haemorrhage (up to 5 litres) without immediate local signs is a daunting one. The inclusion of a table showing examples and the mechanism of such injuries is most helpful; it may well increase our vigilance when observing such accidents in the future. It is a matter for concern that, despite the quality of care of these skilled orthopaedic surgeons at the Meath Hospital, three riders could not ride again and three were unable to return to their previous occupation. The nine equestrians are described as all wearing hats with a retention strap and that they escaped head injuries. It is encouraging to learn of their good sense, perhaps reflecting the wise tuition and many years of riding experience. There is no doubt that head injures represent the greatest threat to horse riders, and it cannot be too strongly emphasised that suitably harnessed personal protective headgear of the highest standard must be worn at all times when mounted. A new British Standard BS EN 1384:96 came into effect on 15th January 1997 and is the English language version of EN 1384:1996 published by the European Committee for

Standardisation (CEN). It supersedes BS 4472:1988 and BS 6473:1984 which are withdrawn. In the United Kingdom this is now the minimum standard recognised by the British Horse Society and the Pony Club with the PAS 015 (Product Approval Specification) helmet recommended as of a higher standard. Professional jockeys wear helmets that are of this latter standard. It must be emphasised that if a hat is subjected to an impact it should be replaced, as external damage is inadequate in detecting significant impairment of future protection. Although it is conjectured that body protectors might have ameliorated these severe injuries, there is no clear evidence that this would have been the case. However, it is considered that such body protectors (class I, II or III) may well prevent soft tissue damage and perhaps minor fractures and injuries to the renal, hepatic, and splenic territories. The choice of body protectors should be influenced by the type of activity, comfort, weight, and freedom from restriction when riding. The one example of a rider trapped by the stirrup draws attention to the need for, in particular, recreational riders to have suitably heeled boots with matching stirrups; trainers should never be worn for riding. It should also be added that anticipation, fitness to ride, and learning how to fall might make all the difference. There is much to learn from this important paper, and it merits the close attention of all those engaged in or caring for those engaged in high risk sports.

JOHN LLOYD PARRY 